\title{
Crescimento de Raízes de Biótipos de Capim-Arroz Resistente e Suscetível aO Quinclorac EM CoMPetiçÃo ${ }^{1}$
}

\author{
Root Growth of Echinochloa Biotypes Resistant and Susceptible to Quinclorac Under \\ Competition
}

\author{
SCHUCH, L.O.B. ${ }^{2}$, ANDRES, A. ${ }^{3}$, FREITAS, G.D. ${ }^{4}$, CONCENÇO, G. ${ }^{5}$, FERREIRA, E.A. ${ }^{5}$, ASPIAZÜ, I. ${ }^{5}$, \\ SILVA, A.F. ${ }^{5}$ e GALON, L. ${ }^{5}$
}

\begin{abstract}
RESUMO - Objetivou-se com este trabalho avaliar o potencial competitivo de biótipos de capim-arroz resistente e suscetivel ao quinclorac no ambiente do solo, como forma de inferir qual deles possui maior potencial de extração de recursos. O experimento foi instalado em casa de vegetação, constando de diferentes populações de plantas dos biótipos de capimarroz resistente $(\mathrm{R})$ e suscetivel $(\mathrm{S})$ ao herbicida quinclorac, oriundos da região arrozeira de Itajaí/SC. Foi estabelecida uma planta do biótipo de capim-arroz considerado como tratamento, no centro da unidade experimental; na periferia, foram semeadas dez sementes do biótipo oposto ao do tratamento central, sendo posteriormente estabelecido o número de plantas de acordo com o tratamento $(0,1,2,3,4$ ou 5 plantas $)$. O delineamento experimental foi o completamente casualizado, em esquema fatorial $2 \times 6$, com quatro repetições. Aos $40 \mathrm{DAE}$, foram avaliados o comprimento, volume, massa fresca, massa seca e conteúdo de água das raízes das plantas. Os dados obtidos foram submetidos à análise de variância e, em caso de significância, efetuou-se o teste de Duncan, para avaliar o efeito do aumento na população de plantas, e o teste da Diferença Mínima Significativa (DMS), para avaliar diferenças entre biótipo resistente e suscetível, além da matriz de correlação. A imposição de competição no ambiente das raizes pode afetar mais o biótipo resistente ao quinclorac que o suscetivel, sendo esta característica essencial para a sobrevivência do biótipo, principalmente sob escassez do recurso.
\end{abstract}

Palavras-chave: resistência, Echinochloa, arroz irrigado, ambiente radical.

\begin{abstract}
The objective of this work was to evaluate the competitive potential of Echinochloa plants resistant and susceptible to quinclorac in the soil, to evaluate whether there are potential differences in extracting nutrients from the soil. The trial was carried out under greenhouse conditions. The treatments consisted of amounts of Echinochloa plants resistant or susceptible to quinclorac. At the center of the experimental unit one plant was established and considered as the treatment; at the periphery, the number of plants of the opposite biotype was established according to the treatment $(0,1,2,3,4$ or 5 plants). The experimental design was completely randomized blocks in a factorial scheme $2 \times 6$, with four replications. Forty days after emergence, root length, volume, fresh and dry mass and water content were evaluated. Data were analyzed by the F-test at 5\% probability, using the DMRT test at 5\% probability for the effect of increasing density, and DMS test at 5\% probability between biotypes. A correlation matrix was built between the evaluated variables. Root competition in the soil could affect more seriously the resistant biotype than the susceptible one, being this characteristic essential for biotype survival, mainly under low nutrient levels.
\end{abstract}

Keywords: resistance, Echinochloa, irrigated rice, root environment.

1 Recebido para publicação em 29.8.2007 e na forma revisada em 13.3.2008.

2 Engo-Agro ${ }^{-}$, Prof. Dr., Depto. de Fitotecnia da FAEM/UFPel, Pelotas-RS, Campus Universitário s/n, Caixa Postal 354, PelotasRS, 96010-900, <lobs@ufpel.edu.br>; ${ }^{3}$ Pesquisador de herbologia da Embrapa Clima Temperado, Pelotas-RS, <andre@cpact.embrapa.br>; ${ }^{4}$ Mestre em Fitotecnia pela FAEM/UFPel, Pelotas-RS; ${ }^{5}$ Doutorando em Fitotecnia da UFV, ViçosaMG.

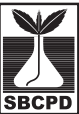

Planta Daninha, Viçosa-MG, v. 26, n. 4, p. 893-900, 2008 


\section{INTRODUÇÃO}

O arroz (Oryza sativa) está entre as culturas mais importantes em termos mundiais, sendo cultivado nos cinco continentes devido à facilidade de adaptação a condições climáticas distintas (Ruiz-Santella et al., 2003). Entre as plantas daninhas mais importantes na cultura do arroz incluem-se o arroz daninho (Oryza sativa), cuja dificuldade de controle se deve ao fato de pertencer à mesma espécie do cultivado (Agostinetto et al., 2002), e o capimarroz (Echinochloa sp.), cuja importância devese às semelhanças morfológicas com as plantas da cultura, à vasta distribuição nos campos de arroz ao redor do mundo e aos altos niveis de infestação (Andres \& Machado, 2004).

O uso contínuo do mesmo mecanismo de ação, quase sempre na ausência de rotação de culturas e do manejo integrado de plantas daninhas, induziu o capim-arroz a desenvolver resistência a vários princípios ativos ao redor do mundo (Ruiz-Santella et al., 2003), com alguns casos de resistência múltipla (LópezMartinez et al., 1997). No Brasil, o biótipo de capim-arroz resistente ao herbicida quinclorac está amplamente distribuído nas regiões orizícolas do Sul do País, onde se concentram quase $70 \%$ da produção nacional desse cereal (Gomes et al., 2002). Além disso, estudos preliminares indicam que os biótipos resistentes apresentam ampla distinção morfofisiológica e que, provavelmente, a resistência se desenvolveu independentemente nas regiões produtoras de arroz (Andres et al., 2007).

Nas comunidades naturais ou em ambientes agrícolas, a competição entre plantas tornou-se um processo importante. O impacto das plantas vizinhas é considerado competição quando houver redução no montante de recursos disponiveis para a planta-alvo (Radosevich et al., 1997). A definição de competição leva em consideração o grau em que as plantas afetam a abundância de um recurso e como outras plantas respondem à troca dessa abundância (Rizzardi et al., 2001). Para ocorrer competição abaixo da superficie do solo, a planta deve ocasionar efeito negativo na disponibilidade de algum recurso para o qual outra planta mostra resposta positiva no crescimento, na sobrevivência ou na reprodução (Casper \& Jackson, 1997). A habilidade competitiva de uma espécie está relacionada à utilização eficiente dos recursos do meio no qual elase encontra (Silva et al., 2007).

As raízes podem captar os recursos disponiveis no solo por meio de três processos: interceptação, fluxo de massa e difusão de água e nutrientes (Fitter \& Hay, 1992). No caso da água, existem alguns fatores que governam sua disponibilidade para o crescimento da planta: o suprimento, a morfologia, o desenvolvimento da raiz e a fisiologia associada à eficiência de uso da água da planta (Radosevich et al., 1997). As raízes de plantas vizinhas diminuem a absorção de nutrientes quando as zonas de depleção se justapõem (Green et al., 1988). Para determinada distância entre raízes, o grau de competição aumenta com o aumento da difusão efetiva, resultando em maior potencial de competição por nitrato do que por potássio $(\mathrm{K})$ ou por íons relativamente imóveis, como o fósforo $(\mathrm{P})$ e o zinco $(\mathrm{Zn})$. O conceito de justaposição das zonas de depleção é menos aplicável para água e nutrientes dissolvidos, como o nitrogênio $(\mathrm{N})$, que são primariamente supridos para as raizes por fluxo de massa (Vogt et al., 1995).

O capim-arroz caracteriza-se pelo metabolismo $\mathrm{C}_{4}$, o que o torna altamente competitivo com as plantas de arroz durante o verão (Potvin et al., 1984). Considerando que ele normalmente ocorre em altas populações nas áreas arrozeiras, o potencial competitivo dos biótipos pode determinar tanto sua influência sobre a cultura como sua manutenção na população pela adição de sementes ao banco do solo, quando confrontado com outro biótipo com aptidões competitivas em particular.

Objetivou-se com este trabalho avaliar o potencial competitivo de biótipos de capim-arroz resistente e suscetivel ao quinclorac no ambiente do solo, como forma de inferir qual deles possui maior potencial de extração de recursos.

\section{MATERIAL E MÉTODOS}

O experimento foi instalado em casa de vegetação da Universidade Federal de Viçosa, entre novembro de 2006 e janeiro de 2007, com temperatura média de $25^{\circ} \mathrm{C}$ e iluminação natural. As unidades experimentais constaram de vasos plásticos com área de $0,07 \mathrm{~m}^{2}$, 
perfurados, contendo $10 \mathrm{~L}$ de solo, corrigido e adubado de acordo com análise e interpretação para a cultura do arroz, com incorporação um mês antes da implantação do experimento. Os tratamentos constaram de plantas dos biótipos de capim-arroz resistente (R - ITJ-13) e suscetível (S - ITJ-17) ao quinclorac, oriundos da região arrozeira de Itajai/SC. No centro da unidade experimental foram semeadas três sementes do biótipo de capim-arroz, considerado como o tratamento da unidade experimental; na periferia, foram semeadas dez sementes do biótipo oposto ao do tratamento (central).

Dez dias após a emergência (DAE), foi efetuado o desbaste, deixando-se apenas uma planta no centro da unidade experimental e o número de plantas do biótipo oposto, de acordo com o tratamento $(0,1,2,3,4$ ou 5 plantas). A área de semeadura do biótipo central da unidade experimental foi delimitada por cilindro com $5 \mathrm{~cm}$ de diâmetro e $2 \mathrm{~cm}$ de profundidade, para facilitar a posterior identificação da planta central e de seus afilhos. O cilindro foi inserido no solo, com a borda superior rente à superficie, permitindo total desenvolvimento das raízes e da parte aérea da planta e plena competição do biótipo central com as demais plantas da periferia, tanto na parte aérea como no sistema de raízes.

O delineamento experimental foi o completamente casualizado, com os tratamentos dispostos em esquema fatorial $2 \times 6$, com quatro repetições. As unidades experimentais foram mantidas eqüidistantes, de forma que a área de superficie disponivel para o desenvolvimento das plantas correspondesse à área da unidade experimental.

Aos $40 \mathrm{DAE}$, a parte aérea das plantas foi eliminada e o conteúdo da unidade experimental lavado em água corrente, sendo o sistema de raízes da planta central individualizado em relação aos demais. Foram avaliadas a planta central e as plantas periféricas (externas), cujo valor foi apresentado como a média por planta de todas as contidas na unidade experimental. Após cautelosa lavagem em água corrente, o comprimento do sistema de raízes foi aferido, sendo em seguida colocado para secar sobre papel-toalha, de forma a eliminar o excesso de água. A seguir, foi inserido em proveta graduada contendo volume predefinido de água, e o volume de líquido deslocado correspondente ao volume das raízes foi anotado. As raízes foram novamente secas em papel-toalha, sem exercer pressão sobre elas, tendo a sua massa fresca imediatamente aferida. Posteriormente, foram acondicionadas em sacos de papel e levadas à estufa com circulação forçada de ar a $60{ }^{\circ} \mathrm{C}$, até massa constante. O conteúdo de água foi calculado pela fórmula (100 * $(\mathrm{MF}-\mathrm{MS}) / \mathrm{MF})$, sendo $\mathrm{MF}=$ massa fresca $\mathrm{e}$ $\mathrm{MS}=$ massa seca de plantas.

Os dados foram submetidos à análise de variância pelo teste $\mathrm{F}$ a $5 \%$ de probabilidade, sendo efetuado teste de Duncan a $5 \%$, para avaliar o efeito do aumento na população de plantas, e teste da Diferença Mínima Significativa (DMS) a 5\% de probabilidade, para avaliar diferenças entre os biótipos $\mathrm{R}$ e $\mathrm{S}$ em cada tratamento, além de matriz de correlação linear de Pearson, utilizando o programa estatístico Winstat 2.11 (Machado, 2002).

\section{RESULTADOS E DISCUSSÃO}

Foi observada interação significativa entre fatores no comprimento de raízes (Tabela 1). Os resultados demonstram que o biótipo $R$, quando cultivado em planta única no centro da parcela, apresentou menor comprimento de raízes nas maiores populações, quatro ou cinco plantas do biótipo oposto, enquanto o S mostrou valores inferiores a partir do tratamento 1 (três), ou seja, a planta central competindo com três periféricas do biótipo oposto. Além disso, não foram observadas diferenças entre os biótipos em nenhum dos tratamentos quando considerada a planta central (Tabela 1). Por outro lado, quando em comunidade (plantas externas), os biótipos reagiram ao incremento na população de plantas do mesmo biótipo de forma distinta. $\mathrm{O}$ biótipo $\mathrm{R}$ não diferiu entre os tratamentos, enquanto o suscetivel pôde ser separado em dois grupos, sendo inferior à testemunha a partir do tratamento 3(um). Isso se deve, pelo menos em parte, ao provável fato de o biótipo $\mathrm{S}$ ser de crescimento mais rápido, produzindo raízes com maior eficiência e, conseqüentemente, sentindo os efeitos da competição em populações menores que o biótipo R, por ocupar o espaço primeiro. Além disso, sob baixa intensidade de competição, o biótipo $\mathrm{S}$ apresentou raízes mais extensas que o biótipo $R$, quando comparados pela DMS (Tabela 1).

Planta Daninha, Viçosa-MG, v. 26, n. 4, p. 893-900, 2008 
Tabela 1 - Comprimento de raízes de capim-arroz aos $40 \mathrm{DAE}$ em função de biótipo e intensidade de competição. Universidade Federal de Viçosa, Viçosa-MG, 2007

\begin{tabular}{|l|c|c|c|}
\hline \multirow{2}{*}{$\begin{array}{c}\text { Posição e } \\
\text { número de } \\
\text { plantas }\end{array}$} & \multicolumn{2}{|c|}{ Biótipo de capim-arroz } & \multirow{2}{*}{ Diferença $^{{ }^{\prime}}$} \\
\cline { 2 - 3 } & Resistente & Suscetível & \\
\hline Centro $^{\underline{3} /}$ & \multicolumn{3}{|c|}{ Comprimento $(\mathrm{cm})$} \\
\hline $1(0)$ & $32,5 \mathrm{a}^{\underline{2} /}$ & $38,0 \mathrm{a}$ & $-5,5 \mathrm{~ns}$ \\
\hline $1(1)$ & $37,0 \mathrm{a}$ & $38,3 \mathrm{a}$ & $-1,3 \mathrm{~ns}$ \\
\hline $1(2)$ & $36,3 \mathrm{a}$ & $37,8 \mathrm{a}$ & $-1,5 \mathrm{~ns}$ \\
\hline $1(3)$ & $35,3 \mathrm{a}$ & $34,8 \mathrm{ab}$ & $+0,5 \mathrm{~ns}$ \\
\hline $1(4)$ & $28,3 \mathrm{ab}$ & $33,0 \mathrm{ab}$ & $-4,7 \mathrm{~ns}$ \\
\hline $1(5)$ & $23,0 \mathrm{~b}$ & $27,3 \mathrm{~b}$ & $-4,3 \mathrm{~ns}$ \\
\hline Externas & & & \\
\hline $0(1)$ & - & - & - \\
\hline $1(1)$ & $38,5 \mathrm{a}$ & $48,0 \mathrm{a}$ & $-9,5 *$ \\
\hline $2(1)$ & $35,8 \mathrm{a}$ & $46,0 \mathrm{a}$ & $-10,2 *$ \\
\hline $3(1)$ & $29,3 \mathrm{a}$ & $37,8 \mathrm{~b}$ & $-8,5 \mathrm{~ns}$ \\
\hline $4(1)$ & $29,5 \mathrm{a}$ & $38,0 \mathrm{~b}$ & $-8,5 \mathrm{~ns}$ \\
\hline $5(1)$ & $31,5 \mathrm{a}$ & $30,0 \mathrm{~b}$ & $+1,5 \mathrm{~ns}$ \\
\hline
\end{tabular}

$1 / \mathrm{ns}=$ não-significativo; $*$ significativo a $5 \%$ de probabilidade pelo teste da DMS

2/ Médias seguidas da mesma letra na coluna e dentro de cada posição (centro ou externas) não diferem pelo teste de Duncan a $5 \%$ de probabilidade.

3/ Centro $=$ número de plantas do biótipo indicado no centro da parcela, competindo com o número de plantas entre parênteses do biótipo oposto.

4/ Externas = número de plantas do biótipo indicado, competindo entre si e com a planta do biótipo oposto (1) no centro da parcela.

Considerando-se as plantas centrais, o volume de raízes do biótipo $\mathrm{R}$ foi influenciado pelo número de plantas do biótipo oposto com as quais competia, podendo ser separado em três grupos. Na maior intensidade de competição, o biótipo R reduziu o volume de raízes. O biótipo S apresentou comportamento semelhante; no entanto, o volume de raízes não foi tão reduzido com o aumento na população das plantas do biótipo oposto (resistente). Também não foram observadas diferenças entre biótipos (Tabela 2). O biótipo suscetivel ao quinclorac acumulou maior volume de raízes que o resistente, quando em baixas populações (Tabela 2), provavelmente devido ao maior comprimento de raízes correspondente (Tabela 1). Aparentemente, o biótipo resistente possui menor capacidade de exploração dos recursos do solo que o segundo, e talvez por isso a interferência do
Tabela 2 - Volume de raízes de capim-arroz aos 40 DAE, em função de biótipo e intensidade de competição. Universidade Federal de Viçosa, Viçosa-MG, 2007

\begin{tabular}{|l|c|c|c|}
\hline \multirow{2}{*}{$\begin{array}{c}\text { Posição e } \\
\text { número de } \\
\text { plantas }\end{array}$} & \multicolumn{2}{|c|}{ Biótipo de capim-arroz } & \multirow{2}{*}{ Diferença $^{1 /}$} \\
\cline { 2 - 3 } & Resistente & Suscetível & \\
\hline Centro $^{3 /}$ & \multicolumn{2}{|c|}{ Volume de raízes $\left(\mathrm{cm}^{3}\right.$ planta $\left.^{-1}\right)$} \\
\hline $1(0)$ & $46,75 \mathrm{a}^{2 /}$ & $42,50 \mathrm{a}$ & $+4,25 \mathrm{~ns}$ \\
\hline $1(1)$ & $33,00 \mathrm{ab}$ & $22,25 \mathrm{ab}$ & $+10,75 \mathrm{~ns}$ \\
\hline $1(2)$ & $37,25 \mathrm{ab}$ & $27,00 \mathrm{ab}$ & $+10,25 \mathrm{~ns}$ \\
\hline $1(3)$ & $29,75 \mathrm{abc}$ & $24,00 \mathrm{ab}$ & $+5,75 \mathrm{~ns}$ \\
\hline $1(4)$ & $20,25 \mathrm{bc}$ & $19,50 \mathrm{ab}$ & $+0,75 \mathrm{~ns}$ \\
\hline $1(5)$ & $12,90 \mathrm{c}$ & $12,50 \mathrm{~b}$ & $+0,4 \mathrm{~ns}$ \\
\hline Externas ${ }^{4 /}$ & & & \\
\hline $0(1)$ & - & - & - \\
\hline $1(1)$ & $36,00 \mathrm{a}$ & $55,50 \mathrm{a}$ & $-19,5 *$ \\
\hline $2(1)$ & $29,25 \mathrm{a}$ & $46,75 \mathrm{ab}$ & $-17,5 *$ \\
\hline $3(1)$ & $26,25 \mathrm{ab}$ & $31,75 \mathrm{~b}$ & $-5,5 \mathrm{~ns}$ \\
\hline $4(1)$ & $24,00 \mathrm{~b}$ & $29,00 \mathrm{~b}$ & $-5,0 \mathrm{~ns}$ \\
\hline $5(1)$ & $14,25 \mathrm{~b}$ & $16,25 \mathrm{c}$ & $-2,0 \mathrm{~ns}$ \\
\hline
\end{tabular}

$\underline{1} \mathrm{~ns}=$ não-significativo; $*$ significativo a $5 \%$ de probabilidade pelo teste da DMS

2/ Médias seguidas da mesma letra na coluna e dentro de cada posição (centro ou externas) não diferem pelo teste de Duncan a $5 \%$ de probabilidade.

3/ Centro $=$ número de plantas do biótipo indicado no centro da parcela, competindo com o número de plantas entre parênteses do biótipo oposto

4/ Externas = número de plantas do biótipo indicado, competindo entre si e com a planta do biótipo oposto (1) no centro da parcela.

sistema de raízes de uma planta sobre outra também tenha sido menor, o que fez com que, quando as plantas estavam em comunidade, o biótipo R tenha sido menos influenciado pelo aumento na população de plantas do mesmo biótipo que o S (Tabela 2). O fato de o biótipo S, quando em comunidade, ter sido mais afetado pelo aumento na população de plantas e apresentar-se superior ao $R$ nas menores populações do mesmo biótipo leva a crer que o biótipo $\mathrm{S}$ incrementa o volume de raízes mais rapidamente e ocupa primeiro o volume do solo.

A massa fresca de raízes apresentou interação significativa entre biótipo e densidade avaliados. No biótipo R, a massa fresca por planta foi menor que na testemunha somente a partir do tratamento 1(quatro), enquanto o biótipo suscetivel ao quinclorac foi afetado, 
mesmo sob baixa intensidade de competição, a partir do tratamento 1 (dois), ou seja, a planta central do biótipo suscetivel competindo com duas plantas do biótipo resistente (Tabela 3). Não foram observadas diferenças entre biótipos em nenhum dos tratamentos pelo teste da DMS, considerando plantas únicas no centro da parcela (Tabela 3). Comportamento similar foi observado nas plantas em comunidade, onde o biótipo resistente ao quinclorac apresentou massa fresca de raízes inferior à da testemunha somente na maior intensidade de competição. O biótipo S, por sua vez, foi afetado a partir do tratamento 3(um). Sob baixa intensidade de competição - uma ou duas plantas do biótipo S competindo entre si e com a planta central - o biótipo suscetivel ao quinclorac foi novamente superior ao resistente (Tabela 3).

Tabela 3 - Massa fresca de raízes de capim-arroz aos 40 DAE, em função de biótipo e intensidade de competição. Universidade Federal de Viçosa, Viçosa-MG, 2007

\begin{tabular}{|l|c|c|c|}
\hline \multirow{2}{*}{$\begin{array}{c}\text { Posição e } \\
\text { número de } \\
\text { plantas }\end{array}$} & \multicolumn{2}{|c|}{ Biótipo de capim-arroz } & \multirow{2}{*}{ Diferença $\mathrm{a}^{-}$} \\
\cline { 2 - 3 } & Resistente & Suscetível & \\
\hline Centro $^{3 /}$ & \multicolumn{2}{|c|}{ Massa fresca $\left(\mathrm{g}^{\prime}\right.$ planta $\left.^{-1}\right)$} \\
\hline $1(0)$ & $36,3 \mathrm{a}^{\frac{2}{}}$ & $49,0 \mathrm{a}$ & $-12,7 \mathrm{~ns}$ \\
\hline $1(1)$ & $34,0 \mathrm{ab}$ & $49,2 \mathrm{a}$ & $-15,2 \mathrm{~ns}$ \\
\hline $1(2)$ & $30,8 \mathrm{ab}$ & $20,5 \mathrm{~b}$ & $+10,3 \mathrm{~ns}$ \\
\hline $1(3)$ & $32,5 \mathrm{ab}$ & $27,5 \mathrm{~b}$ & $+5,0 \mathrm{~ns}$ \\
\hline $1(4)$ & $15,0 \mathrm{bc}$ & $26,3 \mathrm{~b}$ & $-11,3 \mathrm{~ns}$ \\
\hline $1(5)$ & $11,8 \mathrm{c}$ & $18,8 \mathrm{~b}$ & $-7,0 \mathrm{~ns}$ \\
\hline Externas ${ }^{4 /}$ & & & \\
\hline $0(1)$ & - & - & - \\
\hline $1(1)$ & $30,0 \mathrm{a}$ & $53,8 \mathrm{a}$ & $-23,8 *$ \\
\hline $2(1)$ & $26,0 \mathrm{a}$ & $49,3 \mathrm{a}$ & $-23,3 *$ \\
\hline $3(1)$ & $21,3 \mathrm{a}$ & $32,3 \mathrm{~b}$ & $-11,0 \mathrm{~ns}$ \\
\hline $4(1)$ & $17,8 \mathrm{ab}$ & $29,8 \mathrm{~b}$ & $-12,0 \mathrm{~ns}$ \\
\hline $5(1)$ & $13,5 \mathrm{~b}$ & $22,5 \mathrm{~b}$ & $-9,0 \mathrm{~ns}$ \\
\hline
\end{tabular}

${ }^{1 /} \mathrm{ns}=$ não-significativo; $*$ significativo a $5 \%$ de probabilidade pelo teste da DMS

2/ Médias seguidas da mesma letra na coluna e dentro de cada posição (centro ou externas) não diferem pelo teste de Duncan a $5 \%$ de probabilidade

3/ Centro $=$ número de plantas do biótipo indicado no centro da parcela, competindo com o número de plantas entre parênteses do biótipo oposto.

4/ Externas = número de plantas do biótipo indicado, competindo entre si e com a planta do biótipo oposto (1) no centro da parcela.
A massa seca do sistema de raízes das plantas foi muito similar à massa fresca, sendo o biótipo $\mathrm{R}$ mais afetado pelo aumento na população de plantas do biótipo oposto na periferia da unidade experimental (Tabela 4). O acúmulo de massa seca foi inferior ao da testemunha a partir dos tratamentos 1(quatro) e 1(duas) para os biótipos R e S, respectivamente. Além disso, não foram observadas diferenças significativas entre biótipos pela DMS quando em planta isolada no centro da unidade experimental. $\mathrm{O}$ acúmulo de massa seca foi muito similar entre biótipos em função dos tratamentos, quando as plantas se encontravam em comunidade (plantas externas). No entanto, o biótipo $\mathrm{S}$ mostrou acúmulo de massa seca de raizes superior ao do $R$ na menor intensidade de competição - em que uma planta de

Tabela 4 - Massa seca de raízes de capim-arroz aos 40 DAE, em função de biótipo e intensidade de competição. Universidade Federal de Viçosa, Viçosa-MG, 2007

\begin{tabular}{|c|c|c|c|}
\hline \multirow{2}{*}{$\begin{array}{l}\text { Posição e } \\
\text { número de } \\
\text { plantas }\end{array}$} & \multicolumn{2}{|c|}{ Biótipo de capim-arroz } & \multirow{2}{*}{ Diferença ${ }^{1}$} \\
\hline & Resistente & Suscetível & \\
\hline Centro $^{3 /}$ & \multicolumn{3}{|c|}{ Massa seca $\left(\right.$ g planta $\left.^{-1}\right)$} \\
\hline $1(0)$ & $6,32 \mathrm{a}^{2^{\prime}}$ & $7,81 \mathrm{a}$ & $-1,49 \mathrm{~ns}$ \\
\hline $1(1)$ & $5,55 \mathrm{ab}$ & $6,22 \mathrm{ab}$ & $+1,33 \mathrm{~ns}$ \\
\hline $1(2)$ & $4,58 \mathrm{abc}$ & $3,05 \mathrm{~b}$ & $+1,53 \mathrm{~ns}$ \\
\hline $1(3)$ & $3,76 \mathrm{abc}$ & $4,24 \mathrm{~b}$ & $-0,48 \mathrm{~ns}$ \\
\hline $1(4)$ & $2,46 \mathrm{bc}$ & $4,07 \mathrm{~b}$ & $-1,61 \mathrm{~ns}$ \\
\hline $1(5)$ & $1,73 \mathrm{c}$ & $3,00 \mathrm{~b}$ & $-1,27 \mathrm{~ns}$ \\
\hline \multicolumn{4}{|l|}{ Externas $^{4 /}$} \\
\hline $0(1)$ & - & - & - \\
\hline $1(1)$ & $3,82 \mathrm{a}$ & $7,86 \mathrm{a}$ & $-4,04 *$ \\
\hline $2(1)$ & $4,08 \mathrm{a}$ & $6,41 \mathrm{ab}$ & $-2,33 \mathrm{~ns}$ \\
\hline $3(1)$ & $3,00 \mathrm{ab}$ & $4,14 \mathrm{~b}$ & $-1,14 \mathrm{~ns}$ \\
\hline $4(1)$ & $2,33 \mathrm{~b}$ & $3,32 \mathrm{~b}$ & $-0,99 \mathrm{~ns}$ \\
\hline $5(1)$ & $2,08 \mathrm{~b}$ & $3,47 \mathrm{~b}$ & $-1,39 \mathrm{~ns}$ \\
\hline
\end{tabular}

${ }^{1 /} \mathrm{ns}=$ não-significativo; $*$ significativo a $5 \%$ de probabilidade pelo teste da DMS

22/ Médias seguidas da mesma letra na coluna e dentro de cada posição (centro ou externas) não diferem pelo teste de Duncan a $5 \%$ de probabilidade.

3/ Centro $=$ número de plantas do biótipo indicado no centro da parcela, competindo com o número de plantas entre parênteses do biótipo oposto.

4/ Externas = número de plantas do biótipo indicado, competindo entre si e com a planta do biótipo oposto (1) no centro da parcela. 
cada biótipo competia com apenas uma planta do biótipo oposto - tratamento "Externas 1 (um)". A massa seca de raízes (Tabela 4) se mostrou menos sensivel que a massa fresca (Tabela 3) quanto à distinção entre biótipos em função do incremento na intensidade de competição.

O conteúdo de água normalmente é utilizado como um dos indicadores mais sensiveis de que a planta está sob influência de algum agente causador de estresse (Wort, 1964). Normalmente, sob altas ou baixas temperaturas, tratamento herbicida ou sombreamento, o conteúdo de água tende a ser alterado antes mesmo que diferenças possam ser encontradas na massa fresca ou seca, das quais é originado. Além disso, aumentos consideráveis no conteúdo de água podem ser observados quando as plantas estão sob alta competição por luz, uma vez que a pressão de turgescência é a responsável pelo alongamento celular e, conseqüentemente, alongamento da parte aérea das plantas (Vysotskaya et al., 2003). No presente trabalho, nenhuma diferença foi encontrada entre biótipos ou entre tratamentos em relação ao conteúdo de água das plantas (Tabela 5).

Ao contrário do que normalmente seria observado na parte aérea das plantas, o conteúdo de água das raízes parece não ter sido afetado pela alta competição tanto entre plantas do mesmo biótipo como entre plantas do biótipo oposto. Concenço et al. (2006), trabalhando com arroz e herbicida inibidor da ALS em ambiente controlado, verificaram redução do conteúdo de água em função da presença do herbicida somente nas raízes das plantas. Observa-se que o efeito da competição difere completamente do efeito de subdosagens de inibidores da ALS, estando relacionado a outros fatores, além da pressão de turgescência nas raízes. Deve-se considerar ainda que as variáveis do sistema de raízes normalmente apresentam coeficiente de variação mais elevado que as variáveis da parte aérea, principalmente em função da heterogeneidade do ambiente onde as raizes se desenvolvem (Bhom, 1979), e que isso pode ter sido um dos fatores responsáveis pela similaridade entre tratamentos e entre biótipos.

Além disso, ao contrário do que normalmente se observa na parte aérea para altura de plantas, área foliar e massa fresca ou seca,
Tabela 5 - Conteúdo de água de raízes de capim-arroz aos 40 DAE, em função de biótipo e intensidade de competição. Universidade Federal de Viçosa, Viçosa-MG, 2007

\begin{tabular}{|l|c|c|c|}
\hline \multirow{2}{*}{$\begin{array}{c}\text { Posição e } \\
\text { número de } \\
\text { plantas }\end{array}$} & \multicolumn{2}{|c|}{ Biótipo de capim-arroz } & \multirow{2}{*}{ Diferença ${ }^{1 /}$} \\
\cline { 2 - 3 } & Resistente & Suscetível & \\
\hline Centro $^{3 /}$ & \multicolumn{2}{|c|}{ Conteúdo de água (\%) } \\
\hline $1(0)$ & $82,7 \mathrm{a}^{2 /}$ & $84,1 \mathrm{a}$ & $-1,4 \mathrm{~ns}$ \\
\hline $1(1)$ & $83,7 \mathrm{a}$ & $87,3 \mathrm{a}$ & $-3,6 \mathrm{~ns}$ \\
\hline $1(2)$ & $85,1 \mathrm{a}$ & $85,1 \mathrm{a}$ & $0,0 \mathrm{~ns}$ \\
\hline $1(3)$ & $88,4 \mathrm{a}$ & $84,6 \mathrm{a}$ & $+3,8 \mathrm{~ns}$ \\
\hline $1(4)$ & $83,6 \mathrm{a}$ & $84,5 \mathrm{a}$ & $-0,9 \mathrm{~ns}$ \\
\hline $1(5)$ & $85,3 \mathrm{a}$ & $84,0 \mathrm{a}$ & $+1,3 \mathrm{~ns}$ \\
\hline Externas & & & \\
\hline $0(1)$ & - & - & - \\
\hline $1(1)$ & $87,2 \mathrm{a}$ & $85,4 \mathrm{a}$ & $+1,8 \mathrm{~ns}$ \\
\hline $2(1)$ & $84,3 \mathrm{a}$ & $86,0 \mathrm{a}$ & $-1,7 \mathrm{~ns}$ \\
\hline $3(1)$ & $85,9 \mathrm{a}$ & $87,1 \mathrm{a}$ & $-1,2 \mathrm{~ns}$ \\
\hline $4(1)$ & $86,9 \mathrm{a}$ & $88,8 \mathrm{a}$ & $-1,9 \mathrm{~ns}$ \\
\hline $5(1)$ & $84,6 \mathrm{a}$ & $84,6 \mathrm{a}$ & $0,0 \mathrm{~ns}$ \\
\hline
\end{tabular}

${ }^{1 /} \mathrm{ns}=$ não-significativo; $*$ significativo a $5 \%$ de probabilidade pelo teste da DMS

$2 /$ Médias seguidas da mesma letra na coluna e dentro de cada posição (centro ou externas) não diferem pelo teste de Duncan a $5 \%$ de probabilidade.

3/ Centro = número de plantas do biótipo indicado no centro da parcela, competindo com o número de plantas entre parênteses do biótipo oposto.

4/ Externas = número de plantas do biótipo indicado, competindo entre si e com a planta do biótipo oposto (1) no centro da parcela.

no sistema de raízes as variáveis normalmente estão mais intensamente correlacionadas, e essa correlação é direta ou positiva (Tabela 6). No presente estudo, o comprimento e o volume de raízes se correlacionaram de forma positiva com todas as demais variáveis analisadas. A massa fresca relacionou-se de maneira positiva com a massa seca, e o conteúdo de água não esteve relacionado às suas variáveis de origem - massa fresca e seca de raízes. Essas informações permitem afirmar que qualquer das variáveis diretas analisadas no sistema de raízes pode ser utilizada para explicar, pelo menos em parte, o comportamento de outra variável do sistema de raízes (Tabela 6).

O capim-arroz, por possuir o metabolismo $\mathrm{C}_{4}$, é altamente competitivo durante o verão, 
Tabela 6 - Matriz de correlação linear de Pearson entre as variáveis analisadas. Universidade Federal de Viçosa, Viçosa-MG, 2007

\begin{tabular}{|l|l|l|l|}
\hline \multicolumn{1}{|c|}{ Variáveis } & Interação & Variáveis & Interação \\
\hline COMP x VOL & $+0,87 * *$ & VOL x MS & $+0,81 * *$ \\
\hline COMP x MF & $+0,82 * *$ & VOL x CA & $+0,59 *$ \\
\hline COMP x MS & $+0,78 * *$ & MF x MS & $+0,97 * *$ \\
\hline COMP x CA & $+0,82 * *$ & MF x CA & $+0,55 \mathrm{~ns}$ \\
\hline VOL x MF & $+0,94 * *$ & MS x CA & $+0,48 \mathrm{~ns}$ \\
\hline
\end{tabular}

ns = interação não-significativa; * interação significativa a 5\% de probabilidade.

** interação significativa a $1 \%$ de probabilidade.

$\mathrm{COMP}=$ comprimento $; \mathrm{VOL}=$ volume, $\mathrm{MF}=$ massa fresca; $\mathrm{MS}$

= massa seca $; \mathrm{CA}=$ conteúdo de água de raízes de capim-arroz .

tendo elevada capacidade de extração de recursos naturais do ambiente para realizar processos essenciais, como a fotossintese (Taiz $\&$ Zeiger, 2004). Plantas com sistema de raízes mais desenvolvido tendem a explorar maior volume de solo e apresentar melhor desempenho em caso de escassez de recursos (Silva et al., 2007), uma vez que a fotossintese está diretamente atrelada à presença de niveis adequados de água e de nutrientes essenciais, absorvidos pelo sistema de raízes (Taiz \& Zeiger, 2004). De maneira geral, quando em comunidade e sob baixa intensidade de competição, o biótipo $\mathrm{S}$ foi superior ao $\mathrm{R}$ (Tabelas 1, 2, 3 e 4). Além disso, quando confrontados, o biótipo $\mathrm{R}$ foi normalmente mais afetado pelo suscetível, em razão do aumento na competição com plantas do biótipo oposto (Tabelas 2, 3 e 4).

Sob baixa intensidade de competição, as plantas do biótipo de capim-arroz suscetível ao herbicida quinclorac ocupam mais eficientemente o ambiente do solo, podendo ser mais eficientes na utilização de nutrientes, sobretudo em situações de escassez ou baixa disponibilidade do recurso. Aliado a isso, o biótipo resistente foi mais afetado pela presença de plantas do biótipo suscetivel que este pela presença de plantas do biótipo resistente, indicando que, em igualdade de condições, o suscetivel pode levar vantagem. Logo, a imposição de competição no ambiente das raízes pode afetar mais o biótipo resistente ao quinclorac que o suscetivel, sendo essa característica essencial para a sobrevivência do biótipo, principalmente sob escassez do recurso.

\section{LITERATURA CITADA}

AGOSTINETTO, D. et al. Supressão da produção de sementes de arroz-vermelho pela aplicação de herbicidas em arroz irrigado. Pesq. Agropec. Bras., v. 37, n. 1, p. 57-65, 2002 .

ANDRES, A. et al. Detecção da resistência de capim-arroz (Echinochloa sp.) ao herbicida quinclorac em regiões orizícolas do sul do Brasil. Planta Daninha, v. 25, n. 1, p. 221-226, 2007.

ANDRES, A.; MACHADO, S. L. O. Plantas daninhas em arroz irrigado. In: GOMES, A. S.; MAGALHÃES Jr., A. M. (Eds.). Arroz irrigado no Sul do Brasil. Brasília: Embrapa Informação Tecnológica, 2004. p. 457-546.

BHOM, W. Methods of studying root systems. Berlin: Springer-Verlag, 1979. $188 \mathrm{p}$.

CASPER, B. B.; JACKSON, R. B. Plant competition underground. Ann. Rev. Ecol. System., v. 28, p. 545-570, 1997.

CONCENÇO, G. et al. Rice seedling and plant development as affected by increasing rates of penoxsulam under controlled environments. Planta Daninha, v. 24, n. 1, p. 131-139, 2006.

FITTER, A. H.; HAY, R. K. M. Environmental physiology of plants. London: Academic Press, 1992. 355 p.

GREEN, J. D.; MURRAY, D. S.; STONE, J. F. Soil water relations of silverleaf nightshade (Solanum elaeagnifolium) with cotton (Gossypium hirsutum). Weed Sci., v. 36, p. $740-746,1988$.

GOMES, A. S.; TERRES, A. L.; AZAMBUJA, I. H. V. O arroz irrigado no Rio Grande do Sul: produtividade e perfil do produtor. In: AZAMBUJA, I. V. et al. (Eds.). Série culturas - arroz. Porto Alegre: Comissão de Agricultura, Pecuária e Cooperativismo da Assembléia Legislativa do Estado do Rio Grande do Sul, 2002. p. 23-34.

LÓPEZ-MARTINEZ, N.; MARSHALL, G; DePRADO, R Resistance of barnyardgrass (Echinochloa crus-galli) to atrazine and quinclorac. Pestic. Sci., v. 51, n. 1, p. 171-175, 1997.

MACHADO, A. A. et al. Sistema de análises estatísticas para Windows - WINSTAT (Versão 2.11). Pelotas:

Universidade Federal de Pelotas, 2002.

POTVIN, C. et al. Effects of temperature and $\mathrm{CO}_{2}$ enrichment on carbon translocation of plants of the $\mathrm{C}_{4}$ grass species Echinochloa crus-galli (L.) beauv. from cool and warm environments. Plant Physiol., v. 75, n. 4, p. 10541057, 1984.

Planta Daninha, Viçosa-MG, v. 26, n. 4, p. 893-900, 2008 
RADOSEVICH, S.; HOLT, J.; GHERSA, C. W. Weed ecology: Implications for management. New York: John Willey, 1997. 589 p.

RIZZARDI, M. A. et al. Competição por recursos do solo entre ervas daninhas e culturas. Ci. Rural, v. 31, n. 4, p. $707-713,2001$

RUIZ-SANTELLA, J. P.; FISCHER, A. J.; DePRADO, R. Alternative control of two biotypes of Echinochloa phyllopogon susceptible and resistant to fenoxaprop-ethyl. Comm. Agric. Appl. Biol. Sci., v. 68, n. 4, p. 403-407, 2003.

SILVA, A. A. et al. Competição entre plantas daninhas e culturas. In: SILVA, A. A.; SILVA, J. F. (Eds.) Tópicos em manejo de plantas daninhas. Viçosa, MG: Universidade Federal de Viçosa, 2007. p. 17-61.
TAIZ, L.; ZEIGER, E. Fisiologia vegetal. Porto Alegre: Artmed, 2004. 750 p.

VYSOTSKAYA, L. B. et al. Effect of partial root excision on shoot water relations. J. Plant Physiol., v. 160, n. 9, p. 1011-1015, 2003.

VOGT, K. A. et al. Roots, nutrients and their relationship to spatial patterns. Plant Soil, v. 168, n. 1, p. 113-123, 1995.

WORT, D. J. Effects of herbicides on plant composition and metabolism. In: AUDUS, L. J. (Ed.). The physiology and biochemistry of herbicides. New York: Academic Press, 1964. p. 291-334 